\title{
Role of Active Learning Techniques in Development of Problem Solving Skills
}

Bharati Dixit ${ }^{1}$, Mangesh Bedekar ${ }^{2}$, Aditi Jahagirdar ${ }^{3}$, Neha Sathe ${ }^{4}$

${ }^{1}$ Computer Engineering and Technology, Dr. Vishwanath Karad MIT World Peace University, India

${ }^{2}$ Computer Engineering and Technology, Dr. Vishwanath Karad MIT World Peace University, India

${ }^{3}$ Computer Engineering and Technology, Dr. Vishwanath Karad MIT World Peace University, India

${ }^{4}$ Computer Engineering and Technology, Dr. Vishwanath Karad MIT World Peace University, India

${ }^{1}$ bharati.dixit@mitwpu.edu.in

${ }^{2}$ mangesh.bedekar@mitwpu.edu.in

3aditi.jahagirdar@mitwpu.edu.in

${ }^{4}$ neha.sathe@mitwpu.edu.in

\begin{abstract}
In the current era where ample data is generated every second and available to every individual in the form of information, it is easy to gain knowledge from this information but a systematic and methodical approach is required when it comes to skill development.
\end{abstract}

Online and on campus programs help in gaining knowledge but the skills to apply this knowledge needs to be developed gradually through appropriate teaching pedagogy which helps in practicing higher order thinking skills as proposed by Bloom and well known as Bloom's Taxonomy.

In conventional teaching learning approach adopted for online and in-person classroom sessions, the transmission of knowledge takes place most of the time where learner's involvement may be quite less. So from the perspective of improvement in learner's involvement in teaching learning process, active learning methods play a significant role and hence practiced widely in recent times.

Variety of methods are recommended by scientists and Education experts to improve upon assimilation of knowledge for problem solving. Depending upon the nature of the problem the learner either needs to use one of the lower order thinking skills like apply or higher order thinking skills like analyse, evaluate and create as defined by Bloom.

The study presented in this paper discusses case studies of practicing active learning techniques and developing problem solving skills through these techniques. The consolidated feedback analysis for the active learning techniques practiced show that the $96 \%$ learners have agreed for clarity of understanding, $92.72 \%$ learners have shown confidence in application of concepts and $97.27 \%$ participants have shown improved satisfaction in learning. Qualitative testimonies suggests the promising strength of PBL and effectiveness of it in improvement of problem solving skills. The study encourages the effective use of active learning techniques for skill development which is need of time.

Keywords: Higher order thinking skills, active learning techniques, problem solving, Skill development

\section{Introduction}

Though human beings are naturally born learners but formal learning systems and techniques help in enhancing the imaginative and innovative thinking, curiosity, creativity and learning itself to a large extent [1]. Learner's involvement is obvious but the degree of involvement can make significant impact on learning curve and learning outcomes. Depending upon the type and level of involvement of participant in the learning process categorizes the technique as passive learning techniques and active learning techniques. The level of understanding and retention span of knowledge is more in case of active involvement of participants in learning process. It is represented through learning involvement pyramid as shown in Fig. 1.

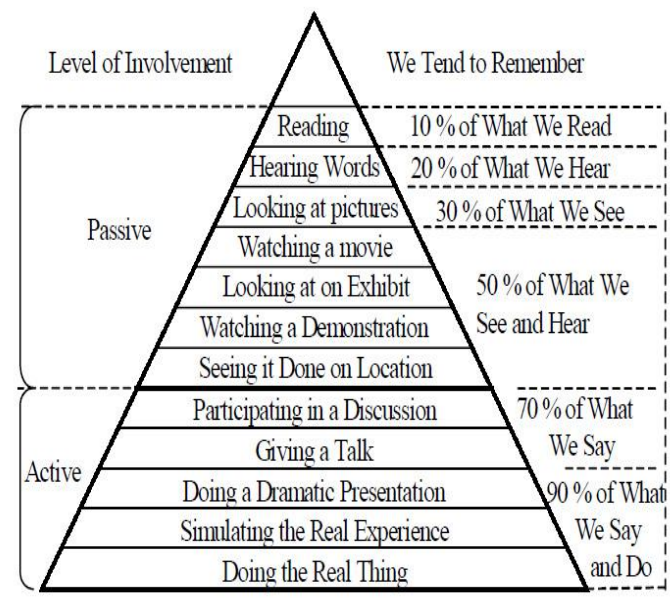

Fig. 1 Learning involvement pyramid (Krivickas (2005)) [2]

Lot of experimentation in this domain has evolved the active learning techniques and now the effectiveness of many of these techniques is well established. Considering the importance of practicing these techniques across the globe for all levels of education system with participants of all age groups, there is exponential rise in the published articles on active learning from 2015 onwards [3].

In today's rapidly changing environment the rate of discovery of new knowledge is enormous. Technology provides tremendous support, online learning platforms, connectivity with knowledge groups, technical forums etc. 
to update, upgrade and broaden the knowledge base of every individual.

It is vital for the learner to get trained, able to analyse and apply, make decisions and acquire skills which are effective in current context [4]. Changing the approach from content specific to student centric is need of the hour and in formal education system to adapt this philosophy, it is teacher's responsibility to practice active learning techniques right from teaching sessions to solving industry problems through projects [5-6].

The study presented in this paper is based on the active learning techniques practiced in the classroom of 60 students while teaching Engineering curriculum courses. The paper is further developed under various sections. Related work is discussed in Section 2. Details of active learning techniques is provided in section 3. Experiments carried out and results obtained are part of section 4 and the work is concluded in section 5 .

\section{Related Work}

Experimentation is the best way of adapting diverse methods in teaching learning environment. Development of problem solving skills is an essential factor in student's development. Enriching knowledge with experiential learning approach is the key element towards development of problem solving skills. The literature discussing experiments performed by various researchers, effectiveness, limitations and challenges faced while implementation are presented in this section.

Caceffo, et.al [7] have performed comparative analysis of traditional learning methods with techniques like problem based learning and peer instruction. Supporting parameters used for comparison are interviews of previous instructors, survey from students and experience of both students and instructors regarding experimentation. Statistics reveal that that problem based learning is more effective method in terms of time and knowledge acquired as compared to traditional approach as well as peer instruction method.

Lucke, et.al [8] experimented with flipped class room approach. First students were motivated to be part of this experiment, shared the learning material in time ahead. Students' engagement, involvement and motivation increased gradually with multiple sessions.

Lima, et.al [9] have practiced role play, games, clickers and problem based learning across different disciplines of engineering and observed that use of such active learning methods creates an exciting and challenging environment among students.

The literature studied highlight the importance, role and effectiveness of active learning techniques in the context of teaching learning environment. These techniques are student centric and hence help in assimilating the knowledge rather than transmission of knowledge. Assimilation provides room to practice and develop higher order thinking skills defined under Bloom's Taxonomy. With change in geographical area, educational set up, learning environment, facilities and student's mindset the effectiveness of these techniques can vary. The further sections presents the details of active learning techniques practiced with 50-60 participants of school of Computer Science and Engineering.

\section{Methodology}

The Learning itself is an active process which results in learning outcomes in cognitive domain, affective domain and psycho motor domain.

Cognitive domain deals with intellectual skills and abilities required for learning, critical thinking and problem solving. Six cognitive levels defined by Bloom are remember, understand, apply, analyse, evaluate and create. These cognitive levels are abbreviated as CL and CL1 to CL3 are called as LOTS - Lower order thinking skills and CL4 to CL6 are called as HOTS - Higher order thinking skills.

The affective domain involves attitude, feelings, values, and beliefs. These skills are difficult to measure but despite the limitations, every effort should be made to include affective outcomes when possible. Affective domain pyramid comprises the levels of receiving, responding, organizing, characterizing and valuing with value at top of the affective domain pyramid.

Psychomotor (skill) outcomes are easier to measure than affective or cognitive outcomes as these are readily observable. The psychomotor domain includes physical movement, coordination, and use of the motor skill. Development of these skills requires practice and is measured in terms of speed, precision, distance, procedures etc.

This underlines the significance of abilities to be developed at cognitive level 3 to cognitive level 6 . These skills enable the students to address problems in multiple domains. To inculcate the skills required to address the requirements of every cognitive level various learning activities are suggested in Bloom's Wheel.

These techniques are experimented at group level or individual level. These techniques can be divided into two groups. The one with less guidance from teacher and second with more guidance from teacher [10-11]. In the first group with less guidance from teacher, student's curiosity and motivation level drives the learning. It is more student centric approach where teachers defines learning goals and give project assignments. In second group teacher's involvement in learning activity is more and teacher is able to observe needs and preferences of each student. The student takes interest in the course and takes active role gradually. The development of such attitude is very important for future study.

The statistics shows that the second approach that is active learning with more guidance has resulted in higher scores for the parameters like meeting learning requirement, improvement in attendance, course and laboratory evaluation and so on.

The active learning activities can be implemented as follows.

- Conduction of activity into the regular classroom session

- Collaborative Learning model

- Cooperative learning model 


\section{- $\quad$ Problem based learning}

Conducting short active learning activities within traditional classroom session has many benefits like addressing the issue of short concentration span, excitement about the activity, satisfaction of task completion and problem solving, peer learning, communication among groups, reflection spots to satisfy the need of students of different pace and learning styles of the students. Such activities can be Think-Pair-Share, Peer Instruction, mind map, matrix activity, flip classroom, short answer questions, case studies, concept map, role play etc. Such active learning activities results into better self-esteem, academic involvement and achievement, interpersonal skills etc.

Collaborative learning methods are those methods in which students work in groups towards a common goal. This approach is designed with the objective to improve student's interactions with each other and achieve common goal rather than performance of individual member. Weaker members of the group benefit the most as they collaborate with group members, learn and apply skills for problem solving.

In case of Cooperative learning model a structured group of students work towards common goal while being accessed individually. The key elements of this model are interpersonal skills, team functioning, self-esteem, mutual interdependence etc. This model has the benefit of motivation to perform better along with achieving common goals.

Project work and any activity which involves practical application of knowledge helps in development of some of the skills like planning, selection/application of appropriate knowledge, communication, self-discipline and focus, cross-function integration, balancing creativity and technical innovation with commercial pragmatism [9].

Problem based learning involves significant amount of self-directed learning. The problems which are open ended in nature are introduced in the beginning of the instruction cycle. Necessary inputs related to motivation, importance of problem, mapping with real life scenarios are provided time to time [9]. Activity is accessed on the rubric designed specific to the type of problem. This approach is widely recommended in Engineering Education as it can provide space to think innovatively, showcase creativity, and address real life scenarios and so on. This approach addresses cognitive aspects better than conventional approach. Apart from project work many courses provides room to set PBL activities. Expertise of teacher plays an important role in effectiveness of this approach.

\section{Corresponding Author}

Computer Engineering and Technology, Dr. Vishwanath

Karad MIT World Peace University, India

bharati.dixit@mitwpu.edu.in

\section{Experimentation and Results}

Some active learning activities are experimented within regular classroom sessions with the participants count in the range of 50-60. Learning objectives defined as improvement in understanding, application of concepts and learner's satisfaction.

For the course Microprocessor and Microcontroller, architecture of processor is taught and then the system block diagram is given to the students in the form of pieces of puzzle. A crossword activity based on the functioning details of architectural blocks is also associated with puzzle. Students connected the pieces to get the complete architectural view of the processor and solved crossword based on technical aspect and working of each building block. This activity is carried out in group of 5/6 students and at the end each group shared technical aspects of any individual block and their experience about the activity. TPS - Think pair and share activity is practiced for assembly language programming. A problem statement is given to all the students, each student came up with algorithm. Pairs are made to discuss further and then the students explained their approach and critical details in terms of implementation with whole class. Overall the students got knowledge about different approaches can be used towards problem solving.

Flip classroom approach is practiced for the topic memory management for the Microprocessor course. Videos and learning material related to paging concept was shared with students a week before. On the day of activity concept is briefed in short and then problems were given to students to solve within class. Approach, clarity in understanding and involvement is observed which was observed to be improved from the teacher's perspective. Feedback is taken from students at the end of activity.

Some more activities like PI - peer instruction and PBLproblem based learning is practiced for different topics. Feedback of every student is taken for all the activities and also for each active learning approach at broad level from the whole group. Analysis of the feedback is represented in Fig. 2 to Fig, 5.

Table 1 Feedback on active learning approaches

\begin{tabular}{|l|c|c|c|c|c|c|}
\hline $\begin{array}{c}\text { Active } \\
\text { learning } \\
\text { Approach }\end{array}$ & \multicolumn{2}{|c|}{$\begin{array}{c}\text { Clarity in } \\
\text { understanding }\end{array}$} & $\begin{array}{c}\text { Confidence in } \\
\text { application of } \\
\text { concepts }\end{array}$ & $\begin{array}{c}\text { Satisfaction } \\
\text { level of } \\
\text { learner }\end{array}$ \\
\hline & I & NI & I & NI & I & NI \\
\hline FC & 52 & 03 & 52 & 03 & 55 & 0 \\
\hline TPS & 56 & 0 & 52 & 04 & 56 & 0 \\
\hline Mind Map & 55 & 05 & 53 & 07 & 57 & 03 \\
\hline $\begin{array}{l}\text { Jigsaw } \\
\text { Puzzle }\end{array}$ & 49 & 0 & 47 & 02 & 46 & 03 \\
\hline \multicolumn{7}{|c|}{ I - Improved; NI - No Impact } \\
FC - Flip Classroom; TPS - Think Pair Share \\
\hline
\end{tabular}




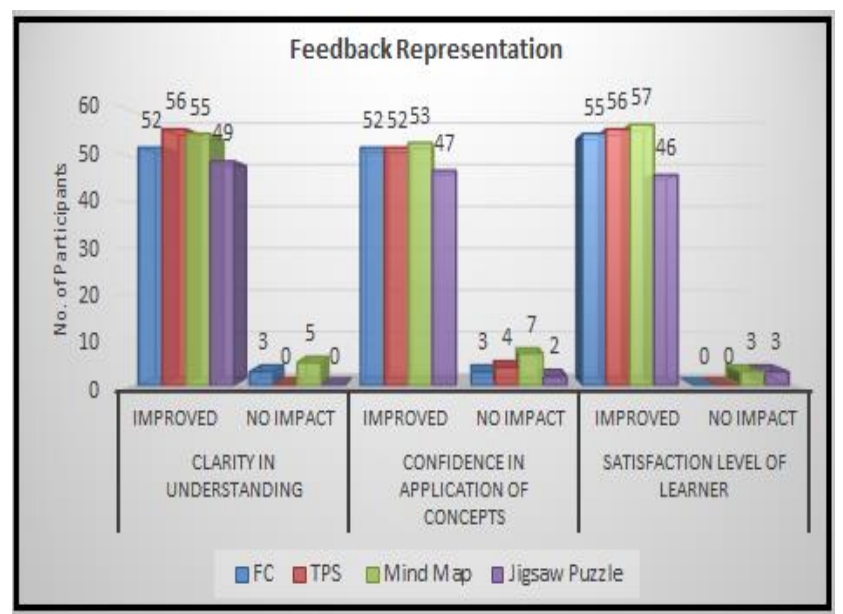

Fig. 2. Graphical representation of learners feedback

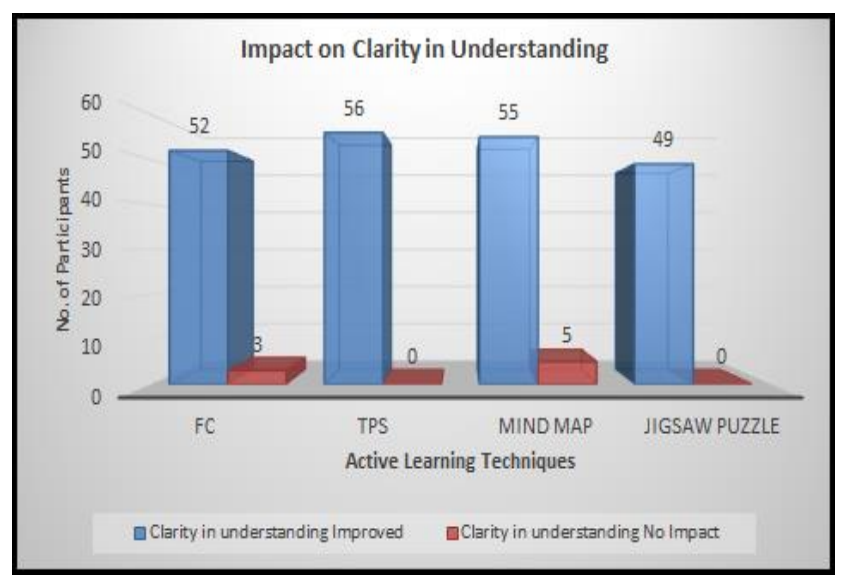

Fig. 3. Representation of the feedback parameter Clarity in understanding

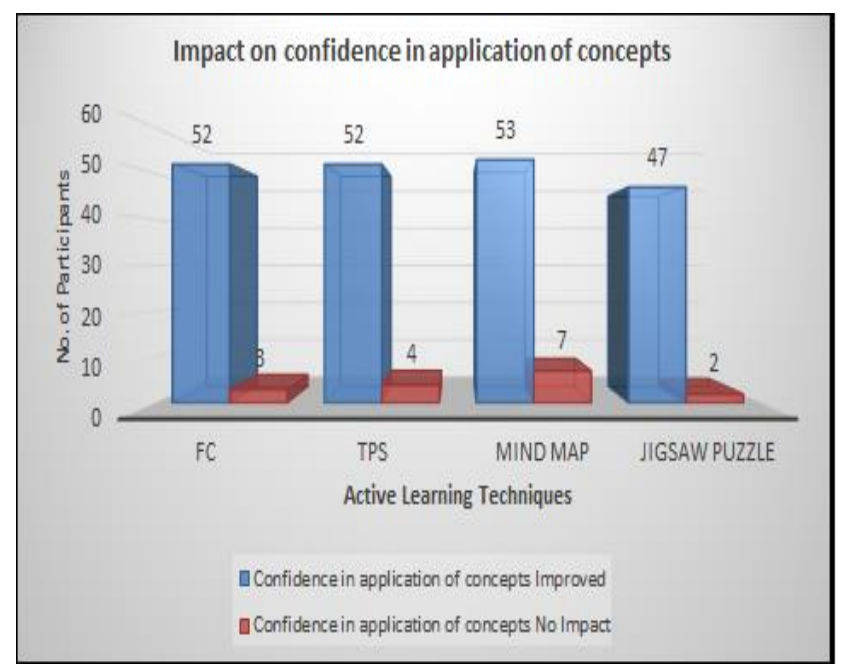

Fig. 4. Representation of the feedback parameter confidence in application of concepts

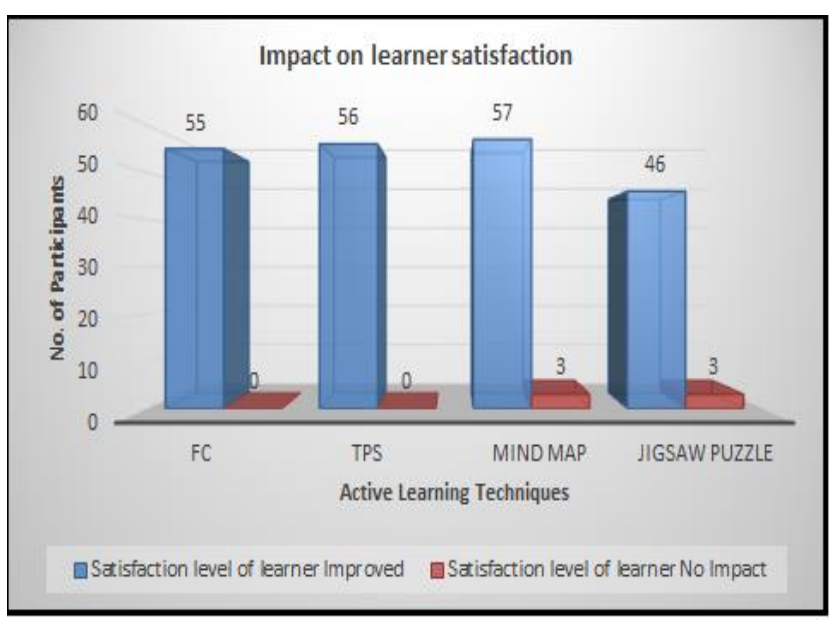

Fig. 5. Representation of the feedback parameter learner satisfaction

The experimentation shows that satisfaction level of learners improve with practicing active learning techniques along with the most sought benefits like better understanding and enhanced confidence in application of concepts. The weak learners are also benefitted as they started involving with litte delay but better learnt from peers. So the feedback analysis reveals the achievement of learning outcomes such as improvement in understanding, satisfaction level and confidence in application of the concepts.

Problem based learning is experimented for the course Digital Electronics and Logic Design. PBL activity was assigned to students as group activity. The problems were open ended problems to be designed using state machine concepts. Some sample problems were design of vending machine, washing machine, ATM machine etc. Implementation of these designs using VHDL was also desirable. Some problems were based on sequential logic circuit design such as parking lot management, bottle filling assembly line management etc. These problems are also to be implemented using deldsim simulator. Evaluation parameter matrix for some sample groups is as represented in Table 2.

Table 2. Assessment Rubric for PBL

\begin{tabular}{|c|c|c|c|c|c|c|}
\hline $\begin{array}{l}\text { Gr } \\
\text { ID }\end{array}$ & $\begin{array}{c}\text { Initiat } \\
\text { ive }\end{array}$ & $\begin{array}{c}\text { Self- } \\
\text { learning }\end{array}$ & $\begin{array}{c}\text { Team } \\
\text { work }\end{array}$ & $\begin{array}{c}\text { Com } \\
\text { muni } \\
\text { catio } \\
\mathbf{n}\end{array}$ & $\begin{array}{c}\text { Critical } \\
\text { capacity }\end{array}$ & $\begin{array}{c}\text { Integratio } \\
\text { n of } \\
\text { Modules }\end{array}$ \\
\hline 1 & 4 & 5 & 5 & 4 & 3 & 5 \\
\hline 2 & 3 & 4 & 5 & 3 & 3 & 5 \\
\hline 3 & 3 & 4 & 5 & 4 & 3 & 5 \\
\hline 4 & 4 & 4 & 5 & 3 & 3 & 5 \\
\hline 5 & 2 & 3 & 5 & 4 & 2 & 5 \\
\hline
\end{tabular}




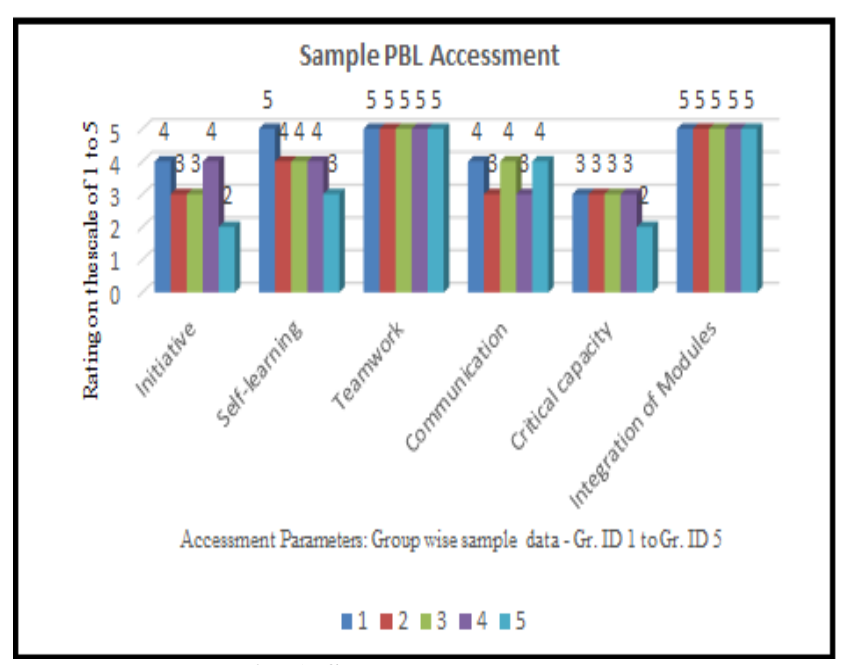

Fig. 6. Sample PBL accessment

Graphical representation of Sample assessment sheet is presented in Fig. 6.

The feedback from students about PBL activity can be retained as qualitative testimonial and revels that there is improvement in self-learning capacity, interpersonal skills, and communication skills. Approach to address the problem is understood. The benefits related to collaborative and cooperative learning are obtained.

\section{Conclusions}

The experiments carried out to teach concepts through some of the well-known active learning approaches are discussed and analyzed in the study. The impact of practicing these techniques is very positive and the associated academic benefits are noteworthy. The consolidated feedback analysis for all the active learning techniques practiced show that the $96 \%$ learners have agreed for clarity of understanding, $92.72 \%$ learners have shown confidence in application of concepts and $97.27 \%$ participants have shown improved satisfaction in learning. Qualitative testimonies suggests the promising strength of PBL and effectiveness of it in improvement of problem solving skills.

The challenges and issues attached with practicing active learning techniques are class control and better time management which can be addressed to some extent with the support of co-teacher and student volunteers. Better planning can lead to smooth conduction on activity, effective delivery of contents and achievement of learning outcomes.

More such innovative approaches can be practiced in future for varied topics with more frequency. There is unbounded scope to design the activities with apt learning outcomes.

\section{Acknowledgements}

We are thankful to all the students for their whole hearted participation, conscious feedback and desire to contribute more for such activities in future. We are also thankful to school of computer Engineering and Technology, MIT World Peace University, Pune, India to encourage us to practice these active learning techniques and providing necessary support for the same.

\section{References}

[1] Christie, Michael, and Erik de Graaff. "The philosophical and pedagogical underpinnings of Active Learning in Engineering Education", European Journal of Engineering Education Vol. 42, No.1 (2017), 5-16.

[2] A.M.S. Hamoudaa, F. Tarlochana, "Engaging Engineering Students in Active Learning and Critical Thinking through Class Debates', Procedia - Social and Behavioral Sciences 191 (2015), 990 - 995.

[3] Rui M. Lima a, Pernille Hammar Anderssonb and Elisabeth Saalmanc, "Active Learning in Engineering Education: a (re)introduction", European Journal of Engineering Education, 2017 Vol. 42, No. 1, 1-4

[4] Lim, S.S., Loo, E.L. and Shekar, A., "Product development partnership programme and its evaluation", in The 8th Australasian Conference of Engineering Management Educators, 129-137, 2001.

[5] Raquel Lacuesta, Guillermo Palacios and Luis Fernández, "Active Learning through Problem Based Learning Methodology in Engineering Education", 39th ASEE/IEEE Frontiers in Education Conference, October 18 - 21, 2009, 1-6.

[6] Graaff, E. and Kolmos, A., "Characteristics of problem-based learning", International. Journal of Engineering Education, 19, 2003, 657-662.

[7] Caceffo, Ricardo, Guilherme Gama, and Rodolfo Azevedo. "Exploring active learning approaches to computer science classes", Proceedings of the 49th ACM Technical Symposium on Computer Science Education 2018.

[8] Lucke, Terry, Peter K. Dunn, and Michael Christie, "Activating learning in engineering education using ICT and the concept of 'Flipping the classroom'", European Journal of Engineering Education 42.1 (2017), 45-57.

[9] Lima, Rui M., Pernille Hammar Andersson, and Elisabeth Saalman. "Active Learning in Engineering Education: a (re) introduction.", (2017), 1-4.

[10] Gao, Jinzhu, and Jace Hargis. "Promoting Technology-Assisted Active Learning in Computer Science Education", Journal of Effective Teaching 10.2 (2010), 81-93.

[11] Aruna Shekar "Active learning and reflection in product development engineering education", European Journal of Engineering Education, 32.2, May 2007, 125-133 